\author{
Paola Cristina Ceratto ${ }^{1}$, Maiara Vanusa \\ Guedes Ribeiro $^{1}$, Renata Calciolari \\ Rossi e Silva ${ }^{2}$ and Debora Tavares de \\ Resende e Silva ${ }^{3^{*}}$ \\ ${ }^{1}$ Degree in nursing from the Federal University \\ Southern Frontier, Brazil \\ ${ }^{2}$ Professor in University of Oeste paulista, $\mathrm{PhD}$ in \\ Health Science, Brazil \\ ${ }^{3}$ Professor in Federal University Fronteira Sul, $\mathrm{PhD}$ \\ in Health Science, Brazil \\ Dates: Received: 17 June, 2015; Accepted: 24 \\ February, 2016; Published: 25 February, 2016 \\ *Corresponding author: Debora Tavares de \\ Resende e Silva, PhD. Federal University Fronteira \\ Sul - Campus Chapecó/SC. Rua General Osorio, \\ 413D. CEP: 89802-265. Caixa Postal 181. Bairro \\ Jardim Italia, Chapeco, Santa Catarina, Brazil. E-mail: \\ deboratavares.silva@hotmail.com \\ www.peertechz.com \\ Keywords: Vitamin D; Chronic kidney Disease; \\ Mortality
}

\section{Mini Review \\ Implications of Vitamin D Deficiency in Chronic Kidney Disease - A Systematic Review}

\section{Chronic Kidney Disease (CKD)}

Chronic Kidney Disease (CKD), considered the new epidemic of the twenty-first century [1], it is a clinical syndrome characterized by a significant reduction, slow, gradual and progressive renal excretory function, endocrine and metabolic. Its incidence is increasing and has high morbidity and mortality rates even in the pre-dialysis phase. This syndrome affects hydric metabolism, electrolyte and basic acid metabolism. So, reflected in changes in the metabolism of macronutrients, providing situations hyper catabolic, proinflammatory and pro-oxidative [2]. In 2013 census, which was conducted by the Brazilian Society of Nephrology (SBN), it was found that about 15 million Brazilians have CKD at some of its stages. Data indicate that 100397000 patients received renal replacement therapy in the same year. The number may even be higher as the elderly, obese, diabetic, hypertensive or people with familiar historical account for 52 million people in the country [3].

High mortality rates have been observed between individuals with CKD many authors state that this fact is a result of complications arising from deterioration in renal function and uremia [4-6]. The complications most commonly found in these individuals are abnormalities of the immune system. The consequent increased risk of infection [7], anemia, disturbance of mineral metabolism, exacerbation of oxidative stress [6], systemic inflammation due to repeated hemodialysis (HD) that lead to activation / production of white blood cells, cytokines [7] and C-reactive protein (CRP) [9].

\section{Inflammation and CKD}

In recent years, chronic inflammation has become recognized as a major culprit in a range of disease states such as cardiovascular disease, obesity, diabetes, malnutrition and even aging. Therefore, it is increasingly observed that CKD is characterized by a state of chronic inflammation that appears to be linked to oxidative stress, endothelial dysfunction and vascular calcification [10].

Inflammation is a physiological process in response to different stimuli and infections, physical-chemical and antigenic changes or traumatic damage. The inflammatory response needs to be precisely regulated, since deficiencies or excesses of this response are directly related to mortality and morbidity. In this context, there is evidence activation of the immune system in early and late stages of CKD. Moreover, some studies suggest a negative relationship between circulating levels of mediators of inflammation and disease stage. It is also known that in patients with CKD terminal or not, the presence of inflammation is an independent predictor of mortality [11].

The chronic inflammatory process affects $40-50 \%$ of chronic renal [8], characterized by the infiltration of inflammatory cells into the glomeruli and tubulointerstitial starting the pathogenic cascade that eventually leads to destruction renal parenchyma by tissue fibrosis [12]. Signals from an activated immune system can already be observed in the early stages of CKD, and they predictors of various complications such as accelerated atherosclerosis, vascular calcification, insulin resistance, increased muscle catabolism, appetite loss, bone remodeling and increased vascular permeability peritoneal [13].

The reason for the increased risk of chronic inflammation in these patients appears to be complex [10], however, in recent years it has established the role of uremic toxicity as kitten to the immune response and is responsible for increased plasma concentrations systemic inflammatory biomarkers and vascular, consequent increase in pro inflammatory cytokines [14]. The immunological dysfunction related to uremia is a complex interaction between the systems of innate and adaptive immune system, wherein the immunosuppression and immune activation coexist [7]. 
The increase in inflammatory mediators was associated with increased oxidative stress and the accumulation of advanced glycation products (AGEs) [5]. AGEs are formed when the aldehyde groups of carbohydrates or ketone reacts with amino acids. In CKD patients, it is possible that AGEs accumulation caused by decreased renal clearance can also promote inflammation. Interestingly, the main causes of death in patients with CKD are related to cardiovascular and infectious diseases, both pathological processes closely related to immune function [14]. C-reactive protein elevation (CRP) and pro inflammatory cytokines are independently associated with allcause cardiovascular mortality in chronic renal patients, therefore, the determination of CRP and interleukin 6 (IL-6) seems to be the best option for risk stratification [15]. Stressing that understanding the mechanisms behind immune dysfunction that is peculiar to DRC assists in creating strategies for improving the quality of life of this group of patients [15].

\section{Vitamin D}

Vitamin D is a fat soluble steroid collection, its active form 1,25-dihydroxyvitamin $\mathrm{D}(1,25[\mathrm{OH}] 2 \mathrm{D})$ or calcitriol, performs the regulation of the calcium and phosphorus homeostasis in the body [16], by intestinal absorption and bone metabolism [17]. Vitamin D is synthesized in the skin or can be ingested in the diet [18]. The skin produces pro vitamin D (cholecalciferol D3) through the action of ultraviolet rays on the same, but the process involves factors such as age and skin pigmentation, and African descendants and advanced age are independent risk factors for vitamin D deficiency.

After their synthesis, vitamin D binds to proteins and is transported via blood to the liver, which occurs 25 carbon hydroxylation, forming calcidiol or 25-hydroxyvitamin D $(25[\mathrm{OH}]$ D) [20], which is transported to the kidneys and converted to the $1 \alpha$-hydroxylase enzyme to its active form, 1,25-dihydroxyvitamin D, or calcitriol $(1,25[\mathrm{OH}] 2 \mathrm{D})$. The calcitiol is responsible for the effects of vitamin $\mathrm{D}$ on calcium and phosphorus metabolism, stimulating the activity of osteoclasts and regulation of the parathyroid glands $[18,21]$. Over the last years it has been demonstrated that the kidney is not the only tissue that expresses the 1 $\alpha$-hydroxylase enzyme [21], may $25(\mathrm{OH}) \mathrm{D}$ is enabled for 1.25 dihydroxyvitamin $\mathrm{D}(1,25[\mathrm{OH}] 2 \mathrm{D})$ regardless of the kidney [22]. The physiological role of the synthesis of 1,25-dihydro-hiroxivitamina extra renal D macrophages, osteoblasts, parathyroid cells, and vascular smooth muscle cells, endothelial cells and tissues, such as the pancreas, breast, prostate, colon and is not well understood [21]. However, this location of vitamins production system have been associated with negative regulation of the reninangiotensin system, suppression of vascular calcification [5], cell proliferation, function, and immune inflammation [22], especially with the secretion of chemokines [23].

The biological functions of vitamin $\mathrm{D}$ are carried out by binding with receptors genes for vitamin D (VDR), which are found in many body tissues such as skin [24]. The VDR gene is a factor liganddependent transcription, which is activated after its binding to vitamin D or analogues thereof, which under normal physiological conditions, are expressed in significant amounts by the tubular cells [12]. Vitamin D deficiency is common in children and adults, and its adverse effects extend beyond bone and mineral metabolism.
Numerous studies have shown an association with cardiovascular disease, insulin resistance, diabetes, infections and inflammation [19], progression of chronic kidney disease (CKD) and immune system disorders [20,25]. A vitamin D deficiency indicator is calcidiol (25 [OH] D) [20].

\section{Vitamin $\mathrm{D}$ and inflammation in CKD}

The pro-inflammatory state of end-stage CKD is associated with increased risk of cardiovascular disease and death [26]. Vitamin D deficiency is highly prevalent in individuals with CKD. Vitamin D deficiency is probably an important modifiable risk factor in this population [19], that due to uremic state with the skin are impaired photosynthesis calciferol, loss of appetite, urinary losses of vitamin binding protein $\mathrm{D}$ (DBP) and albumin, and decreased vitamin intake due to food restriction $[19,20]$. Several factors, including increasing age and comorbidities such as diabetes and hypertension have also been frequently associated with low levels of 25-hydroxyvitamin D (25 [OH] D) [27].

There are several mechanisms involved in the reduction of 1,25-dihydroxyvitamin $\mathrm{D}$ during the course of $\mathrm{CKD}$, highlighting the reduction of renal mass and consequent decrease in glomerular filtration rate, which limit the interaction of 25 -hydroxyvitamin $D$ with 1a-hydroxylase enzyme and therefore limit the ability of the kidneys to produce 1,25-dihydroxyvitamin D [21]. Another mechanism involved is the loss of the VDR, it still occurs at the beginning of CKD due to renal inflammation. The kidney cell infiltration through the secretory cells of pro inflammatory cytokines are essential in mediating suppression VDR tubular epithelium damaged kidneys. It is also reported that TNF, a major pro-inflammatory mediator and suppresses the VDR expression in various cell types [12]. Currently, the growth of fibroblasts (FGF-23) has been widely related vitamin $\mathrm{D}$ deficiency in chronic renal failure patients. FGF-23 is a protein produced in bone stimulated by dietary intake of phosphorus that acts on the kidneys producing phosphaturia and suppressing the expression of 1a-hydroxylase enzyme, which consequently decreases the production of 1,25-dihydroxyvitamin $\mathrm{D}(1,25[\mathrm{OH}] 2 \mathrm{D})$ [20].

Previous studies have shown that vitamin D administration in chronic renal failure patients produces therapeutic effects $[12,18,19,26]$, suggesting an inverse relationship between the presence of 25-hydroxyvitamin D [25 (OH) D] and inflammatory biomarkers [26]. This inverse relationship mentioned, leads to reduced levels of CRP [18,19,21,26], IL-8 and TNF- $\alpha$ [21,26] and deletion of calcification inducers such as collagen type I. In addition, the activation of suppressor of calcification, such as GLa matrix protein, osteopontin and osteocálcio [28]. It is also demonstrated increased anti-inflammatory effect mediated by IL-10 [26]. The mechanisms underlying these effects may be related to the preservation of renal tubular integrity and the restoration of the VDR receptors, even in already developed renal lesions $[12,18]$.

The vitamin $\mathrm{D}$ is often administered in patients with chronic renal problems to mitigate the detrimental effects on the health of the bone and mineral metabolism [28]. However, as seen, the effect of supplementation of only this will greatly benefit. Importantly, vitamin $\mathrm{D}$ administration indiscriminately can generate unwanted effects, 
such as increased calcium and phosphate, favoring the development of vascular calcifications. Therefore, new vitamin D analogues have been suggested for substitution of calcitriol [28], due to the fact it has the disadvantage of producing phosphorus and raising serum calcium levels. This effect is caused by increasing intestinal absorption of both electrolytes, since calcium and phosphorus are not properly excreted due to kidney failure [29].

\section{Conclusion}

It is emphasized so the importance of proper maintenance of the vitamin D status, since it plays an important role in the management of inflammation and immunity, contributing to the reduction of morbidity and mortality in patients with CKD [23]. There is cumulative evidence showing the low level of vitamin $\mathrm{D}$ associations with the development and progression of chronic kidney disease, cardiovascular complications and high mortality.

\section{References}

1. Braga FLM, De Arruda LKG, Diniz ADS, Cabral PC, Lemos MDCC, et al (2013) Disfunção renal e marcadores inflamatórios em hipertensos atendidos em hospital universitário. Arq Bras Cardiol.

2. Barbosa ACSCS, Salomon ALR (2012) Resposta inflamatória de pacientes com doença renal crônica em fase pré-dialítica e sua relação com a ingestão protéica. Com. Ciências Saúde.

3. Sesso RC, Lopes AA, Thomé FS, Lugon JR, Watanabe Y, et al. (2014) Relatório do Censo Brasileiro de Diálise Crônica 2012. J Bras Nefrol 36: 53.

4. Bowry SK, Gatti E (2011) Impact of Hemodialysis Therapy on Anemia of Chronic Kidney Disease: The Potential Mechanisms. Blood Purif 32: 210219 .

5. Lee DM, Jackson KW, Knowlton N, Wages J, Alaupovic P, et al. (2011) Oxidative stress and inflammation in renal patients and healthy subjects. Plos One 6: E22360.

6. Barberato SH, Gardano SGE, De Souza AM, Costantini CO, Costantini CRF, et al. (2013) Associação entre Marcadores de Inflamação e Aumento do Átrio Esquerdo em Pacientes de Hemodiálise. Arq Bras Cardiol 100: 141-146.

7. Tbahriti HF, Meknassi D, Moussaoui R, Messaoudi A, Zemour L, et al. (2013) Inflammatory status in chronic renal failure: The role of homocysteinemia and pro-inflammatory cytokines. World J Nephrol 2: 31-37.

8. Bucharles SG, Varela AM, Barberato SH, Pecoits-Filho R (2010) [Assessment and management of cardiovascular disease in patients with chronic kidney disease]. J Bras Nefrol 32: 118-125.

9. Bayraktar G, Kurtulus I, Kazancioglu R, Bayramgurler I, Cintan S, et al (2009) Oral health and inflammation in patients with end-stage renal failure. Perit Dial Int 29: 472-479.

10. Stenvinkel P, Ketteler M, Johnson RJ, Lindholm B, Pecoits-Filho R, et al. (2005) IL-10, IL-6, and tnfalpha: central factors in the altered cytokine network of uremia - the good, the bad, and the ugly. Kidney Int 67: 1216-1233.

11. Vianna HR, Soares CMBM, Tavares MS, Teixeira MM, Silva e ACS (2011) Inflamação na doença renal crônica: papel de citocinas. J Bras Nefrol 33 351-364.

12. Xiong M, Gong J, Liu Y, Xiang R, Tan X (2012) Loss of vitamin D receptor in chronic kidney disease: a potential mechanism linking inflammation to epithelial-to-mesenchymal transition. Am J Physiol Renal Physiol 303: F1107-F1115
13. Pecoits-Filho R, Sylvestre LC, Stenvinkel P (2005) Chronic kidney disease and inflammation in pediatric patients: from bench to playground. Pediatr Nephrol 20: 714-720.

14. Hauser AB, Stinghen AE, Kato S, Bucharles S, Aita C, et al. (2008) Characteristics and causes of immune dysfunction related to uremia and dialysis. Perit Dial Int 28: S183-187.

15. Panichi V, Rizza GM, Paoletti S, Bigazzi R, Aloisi M, et al. (2008) Chronic inflammation and mortality in haemodialysis: effect of different renal replacement therapies. Results from the RISCAVID study. Nephrol Dial Transplant 23: 2337-2343.

16. Wang C (2013) Role of vitamin D in Cardiometabolic Diseases. J Diabetes Res 2013: 243934.

17. Khan H, Kunutsor S, Franco OH, Chowdhury R (2013) Vitamin D, type 2 diabetes and other metabolic outcomes: a systematic review and metaanalysis of prospective studies. Proceedings of the Nutrition Society 72: 8997.

18. Eleftheriadis T, Antoniadi G, Liakopoulos V, Stefanidis I, Galaktidou G (2012) Inverse Association of Serum 25-Hydroxyvitamin D with Markers of Inflammation and Suppression of Osteoclastic Activity in Hemodialysis Patients. Iran J Kidney Dis 6: 129-135

19. Kalkwarf HJ, Denburg MR, Strife CF, Zemel BS, Foerster DL, et al. (2012) Vitamin $\mathrm{D}$ deficiency is common in children and adolescents with chronic kidney disease. Kidney Int 81: 690-697.

20. Rodríguez Villarreal I, Ortega O, Gallar P, Sánchez M, Callejas R, et al. (2011) Clinical and biochemical characteristics of predialysis patients in terms of 25 hydroxy vitamin D levels. Nefrología 31: 185-191.

21. Dusso A, González EA, Martin KJ (2011) Vitamin D in chronic kidney disease. Best Practice \& Research Clinical Endocrinology \& Metabolism 25: 647-655.

22. Ponda MP, Breslow JL (2013) Vitamin D3 Repletion in Chronic Kidney Disease Stage 3: Effects on Blood Endotoxin Activity, Inflammatory Cytokines and Intestinal Permeability. Renal failure 35: 497-503.

23. Alvarez JA, Zughaier SM, Law J, Hao L, Wasse H, et al. (2013) Effects of high-dose cholecalciferol on serum markers of inflammation and immunity in patients with early chronic kidney disease. Eur J Clin Nutr 67: 264-269.

24. Gupta GK, Agrawal T, DelCore MG, Mohiuddin SM, Agrawal DK (2012) Vitamin D Deficiency Induces Cardiac Hypertrophy and Inflammation in Epicardial Adipose Tissue in Hypercholesterolemic Swine. Experimental and Molecular Phatology 93: 82-90.

25. Bednarek-Skublewska A, Smoleń A, Jaroszyński A, Załuska W, Ksiazek A (2010) Effects of vitamin D3 on selected bio chemical para meters of nutritional status, inflammation and cardiovascular disease in patients undergoing long-term hemodialysis. Pol Arch Med Wewn 120: 167-174.

26. Wasse H, Cardarelli F, De Staercke C, Hooper C, Veledar E, et al. (2011) 25-hydroxyvitamin $D$ concentration is inversely associated with serum MMP-9 in a cross-sectional study of African American ESRD patients. BMC Nephrology 12: 24.

27. Echida Y, Mochizuki T, Uchida K, Tsuchiya K, Nitta K (2012) Risk Factors for Vitamin D Deficiency in Patients with Chronic Kidney Disease. Intern Med 51: 845-850.

28. Duplancic D, Cesarik M, Poljak NK, Radman M, Kovacic V, et al. (2013) The influence of selective vitamin $D$ receptor activator paricalcitol on cardiovascular system and cardiorenal protection. Clinical Interventions in Aging 8: 149-156.

29. Izquierdo MJ, Cavia M, Muñiz P, de Francisco AL, Arias M, et al. (2012) Paricalcitol reduces oxidative stress and inflammation in hemodialysis patients. BMC nephrology 13: 159 